University of South Florida

DIGITAL COMMONS

@ UNIVERSITY OF SOUTH FLORIDA
Digital Commons @ University of

South Florida

8-1-2007

\title{
Toolbox for Transit Event Investigation
}

CUTR

Follow this and additional works at: https://digitalcommons.usf.edu/cutr_nctr

\section{Recommended Citation}

"Toolbox for Transit Event Investigation," National Center for Transit Research (NCTR) Report No. CUTRNCTR-RR-2006-05, Center for Urban Transportation Research, University of South Florida, 2007.

DOI: https://doi.org/10.5038/CUTR-NCTR-RR-2006-05

Available at: https://scholarcommons.usf.edu/cutr_nctr/167

This Technical Report is brought to you for free and open access by the National Center for Transit Research (NCTR) Archive (2000-2020) at Digital Commons @ University of South Florida. It has been accepted for inclusion in Research Reports by an authorized administrator of Digital Commons @ University of South Florida. For more information, please contact digitalcommons@usf.edu. 


\section{Toolbox for Transit Event Investigation}

Deborah Buchacz Sapper Amber Reep

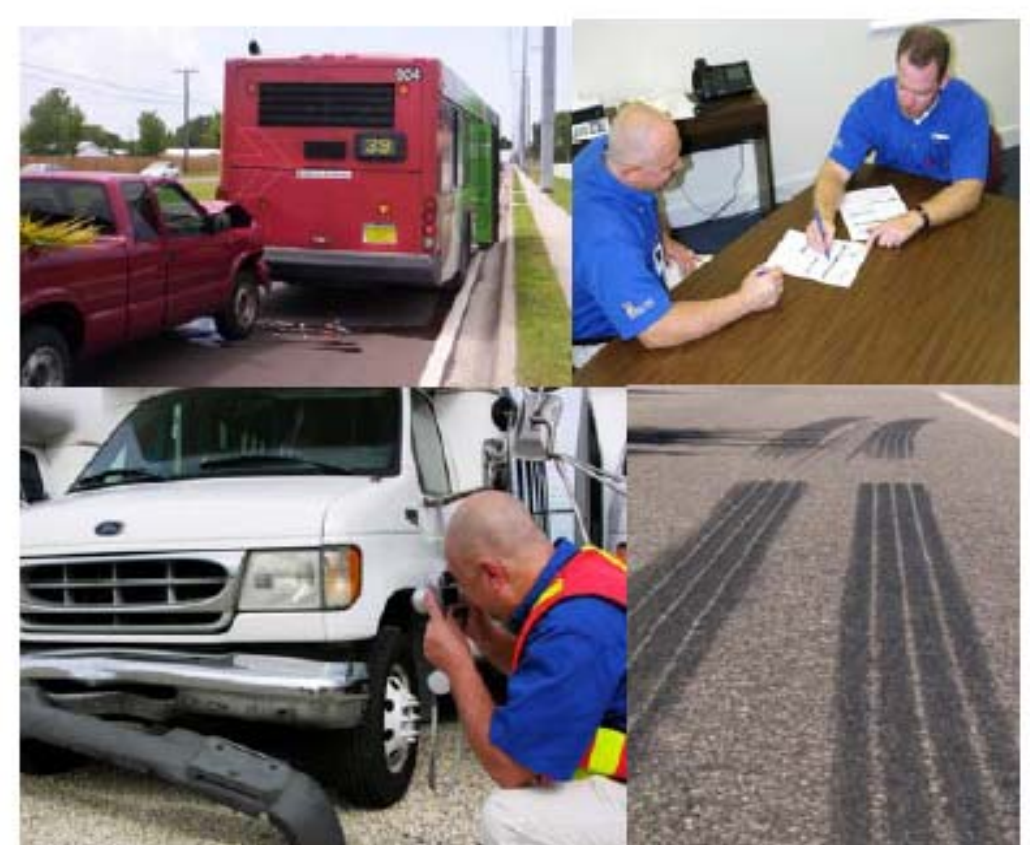

August 2007 


\begin{tabular}{|c|c|c|c|c|}
\hline $\begin{array}{l}\text { 1. Report No } \\
\text { NCTR 77706-00 } \\
\text { BD549-22 }\end{array}$ & \multicolumn{2}{|c|}{ 2. Government Accession No. } & \multicolumn{2}{|c|}{ 3. Recipient's Catalog No. } \\
\hline \multirow{3}{*}{\multicolumn{3}{|c|}{$\begin{array}{l}\text { 4. Title and Subtitle } \\
\text { Toolbox for Transit Event Investigation }\end{array}$}} & \multirow{2}{*}{\multicolumn{2}{|c|}{$\begin{array}{l}\text { 5. Report Date } \\
\text { August } 2007\end{array}$}} \\
\hline & & & & \\
\hline & & & \multicolumn{2}{|c|}{ 6. Performing Organization Code } \\
\hline \multicolumn{3}{|c|}{$\begin{array}{l}\text { 7. Author(s) } \\
\text { Deborah Buchacz Sapper and Amber Reep }\end{array}$} & \multicolumn{2}{|c|}{$\begin{array}{l}\text { 8. Performing Organization } \\
\text { Report }\end{array}$} \\
\hline \multicolumn{3}{|c|}{ 9. Performing Organization Name and Address } & \multicolumn{2}{|c|}{ 10. Work Unit No. } \\
\hline \multicolumn{3}{|c|}{$\begin{array}{l}\text { National Center for Transit Research } \\
\text { Center for Urban Transportation Research } \\
\text { University of South Florida } \\
4202 \text { E. Fowler Avenue, CUT } 100 \\
\text { Tampa, FL 33620-5375 }\end{array}$} & \multicolumn{2}{|c|}{$\begin{array}{l}\text { 11. Contract or Grant No. } \\
\text { DTRS98-G-0032 }\end{array}$} \\
\hline & \multicolumn{2}{|c|}{ 13. Final Report } \\
\hline $\begin{array}{l}\text { Office of Research and Special Pro } \\
\text { U.S. Department of Transportation } \\
\text { Florida Department of Transportat } \\
605 \text { Suwannee Street, MS 26, Tall }\end{array}$ & \multicolumn{2}{|c|}{$\begin{array}{l}\text { Florida Department of Transportation } \\
605 \text { Suwannee Street, MS 26, Tallahassee, FL } 32399\end{array}$} & \multicolumn{2}{|c|}{ 14.Sponsoring Agency Code } \\
\hline \multicolumn{5}{|l|}{ 15. Supplementary Notes } \\
\hline \multicolumn{5}{|l|}{ 16. Abstract } \\
\hline \multirow{2}{*}{\multicolumn{5}{|c|}{$\begin{array}{l}\text { The purpose of this project was to provide a toolbox for transit systems with an overview of the procedures and guidelines } \\
\text { needed to conduct transit incident investigations. This toolbox does not replace existing federally offered training courses, } \\
\text { but rather is intended to assist transit systems in implementing and complying with state requirements and best practices } \\
\text { associated with bus transit safety and security incidents. } \\
\text { This toolbox provides an overview of what to do when an incident occurs and outlines the transit system's role in } \\
\text { conducting an investigation. The objective of the Bus Transit Incident Investigation Toolbox is to provide transit systems } \\
\text { with an overview of the procedures and guidelines needed to conduct transit incident investigations. The Toolbox } \\
\text { contains a DVD with a 42-minute video and a pocket guide that provides transit systems with an overview of the } \\
\text { responsibilities, procedures, and guidelines on how to conduct transit incident investigations. }\end{array}$}} \\
\hline & & & & \\
\hline 17. Key Words & \multirow{2}{*}{\multicolumn{4}{|c|}{$\begin{array}{l}\text { 18. Distribution Statement } \\
\text { Available to the public through the National Technical Information } \\
\text { Service (NTIS),5285 Port Royal Road, Springfield, VA 22181, phone } \\
\text { (703) 487-4650, http://www.ntis.gov through the NCTR web sit at } \\
\text { http://www.nctr.usf.edu/ and the project website } \\
\text { http://www.cutr.usf.edu/bussafety/ }\end{array}$}} \\
\hline $\begin{array}{l}\text { PublicTransportation, safety, } \\
\text { safety oversight, bus transit } \\
\text { incident, investigation, accident } \\
\text { investigation bus transit }\end{array}$ & & & & \\
\hline $\begin{array}{l}\text { 19. Security Classif. (of this report) } \\
\text { Unclassified }\end{array}$ & $\begin{array}{l}\text { 20. Security Classif. } \\
\text { (of this page) } \\
\text { Unclassified }\end{array}$ & \multicolumn{2}{|c|}{$\begin{array}{l}\text { 21. No. of pages } \\
31\end{array}$} & 22. Price \\
\hline
\end{tabular}

Form DOT F 1700.7 (8-69) 


\section{Toolbox for Transit Event Investigation}

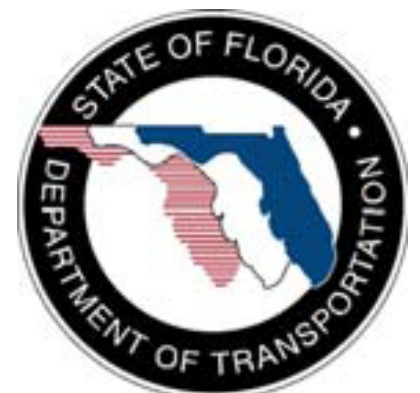

State of Florida Department of Transportation

Public Transit Office

605 Suwannee Street

Tallahassee, FL 32399-0450

(850) 414-4500

Project Manager:

Mike Johnson

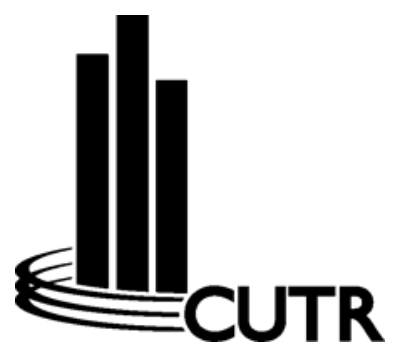

National Center for Transit Research

Center for Urban Transportation Research

University of South Florida

4202 E. Fowler Avenue, CUT100

Tampa, FL 33620-5375

(813) 974-3120

Project Staff: Deborah Buchacz Sapper, Senior Research Associate Amber Reep, Senior Research Associate 


\section{Disclaimer}

The opinions, findings and conclusions expressed in this publication are those of the authors and not necessarily those of the U.S. Department of Transportation or the State of Florida Department of Transportation. 


\section{TABLE OF CONTENTS}

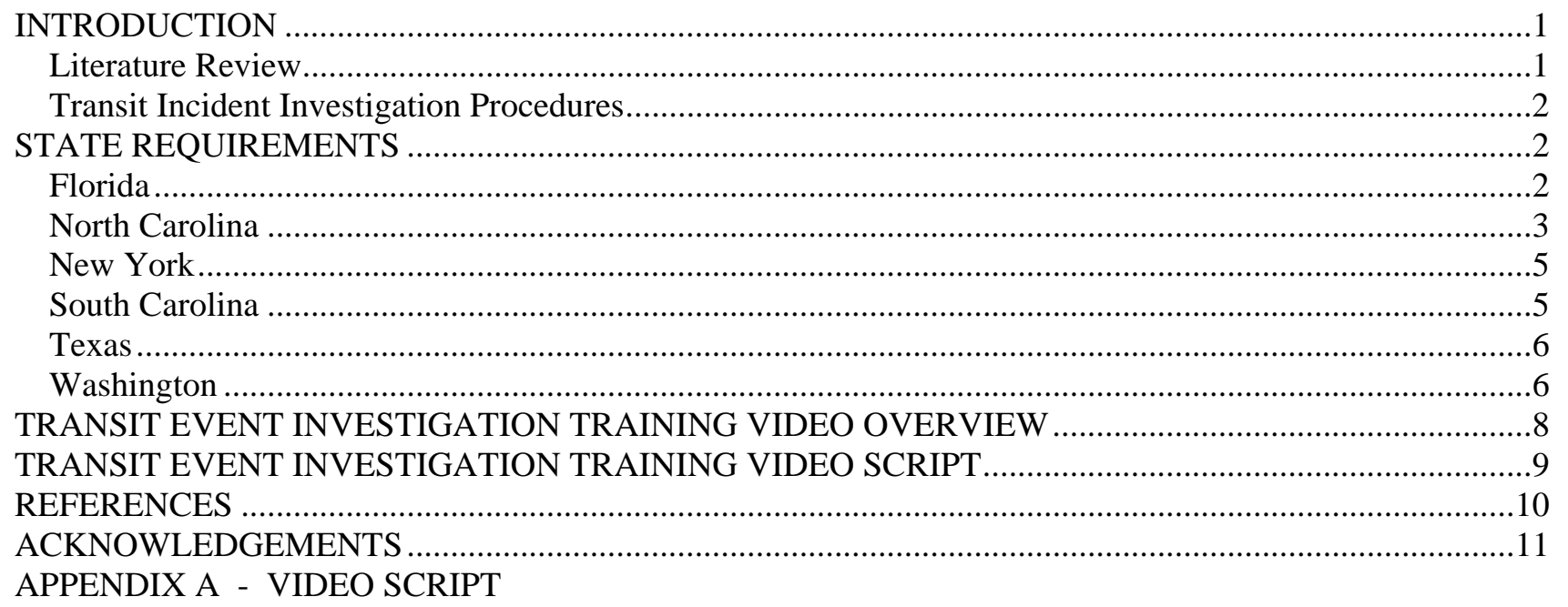




\section{Introduction}

Through its National Center for Transit Research (NCTR), and under contract with the Florida Department of Transportation (FDOT), the Center for Urban Transportation Research (CUTR) at the University of South Florida developed a "Toolbox for Transit Event Investigation.” The Federal Transit Administration (FTA) Model Transit Bus Safety and Security Program identified safety data acquisition and analysis as one of its core elements. Transit agencies are responsible for investigating and recording the event, identifying causal factors, and recommending corrective actions. In small rural transit agencies, investigations of security and safety events are not formally conducted or conducted on a limited basis, while larger transit agencies may require a more comprehensive investigation. These investigation techniques and methods often vary among transit agencies.

The objective of the Bus Transit Incident Investigation Toolbox is to provide transit systems with an overview of the procedures and guidelines needed to conduct transit incident investigations. The Toolbox contains a DVD with a 42-minute video and a pocket guide that provides transit systems with an overview of the responsibilities, procedures, and guidelines for conducting transit incident investigations. The toolbox also contains the recently published Transportation Safety Institute (TSI) "Guidelines for Recordability" to assist transit agencies in determining recordability or preventability of collisions and incidents including samples of policies, procedures and forms that can be use in incident investigation. A copy of the Florida Bus Incident Reporting, Tracking, and Analysis System database is also included as part of the Toolbox.

The Toolbox does not replace existing federally offered training courses, but is intended to assist transit systems in implementing and complying with State requirements and best practices for bus transit incidents investigation.

\section{Literature Review}

The researchers conducted a literature search using the internet, libraries, and several transit trade associations and government agencies, including the Transportation Research Board (TRB), the American Public Transportation Association (APTA), and the U.S Department of Transportation's (USDOT) Transportation Safety Institute (TSI) and the Federal Transit Administration (FTA).

The literature review revealed that most of the information available dealt specifically with rail transit systems. Very little information was available that deals with bus transit. Additionally, limited information was available that identifies standards, best practices or recommended procedures for bus transit event investigation.

The research did find that the majority of bus transit systems are utilizing standards developed by the USDOT for incident investigation training. The USDOT's Transportation Safety Institute offers three bus incident investigation courses: "Fundamentals of Bus Collision Investigation” (FT00435), “Intermediate Programs in Bus Collision Investigation” (FT00472), and "Bus Collision Prevention and Investigation Seminar" (FT00470). All of these courses 
provide detailed information on tools and techniques related to data collection, on-scene evidence documentation, witness interview techniques, computation of speed estimates (time and distance), photographic documentation, and report writing.

\section{Transit Incident Investigation Procedures}

To obtain information about current transit incident investigation procedures, transit agencies were contacted in Florida, North Carolina, New York, South Carolina, Texas, and Washington. Through telephone interviews and electronic mail interviews, researchers asked the transit agencies’ personnel about existing event investigation policies, procedures, roles, responsibilities, training, forms, reporting and practices.

These data were used to develop an understanding of the existing incident investigation practices as well as the challenges that transit systems face when an event investigation is required. From this data, CUTR researchers were able to establish a general Bus Transit Incident Investigation Toolbox resource for transit systems.

\section{State Requirements}

One common factor appeared in the incident reporting standards of the various state departments of transportation. States that have developed standards for System Safety Program Plans (SSPP) also have standards for accident/incident reporting and investigation procedures. However, some states have gone beyond the requirements of their SSPP by outlining the accident/incident reporting and investigation procedures. CUTR identified some of these programs below.

\section{Florida}

Florida is unique in that statutes require bus transit systems to investigate and report transit bus incidents. Chapter 14-90, Florida Administrative Code (FAC) requires public transit operators in Florida to adhere to operational standards and practices and to review and adopt System Safety Program Plans (SSPP) and Security Program Plans (SPP) on an annual basis. As part of the SSPP, transit systems must follow the required operational standards. Transit agencies are responsible for investigating, recording the event, identifying causal factors, and recommending corrective actions. The actual standards cite the following:

\section{Section 14-90.004, FAC, Bus Transit System Operational Standards}

(5)Each bus transit system shall investigate, or cause to be investigated, any event involving a bus or taking place on bus transit system controlled property resulting in a fatality, injury, or property damage as follows:

(a) A fatality, where an individual is confirmed dead within 30 days of a bus transit system related event, excluding suicides and deaths from illnesses.

(b) Injuries requiring immediate medical attention away from the scene 
for two or more individuals.

(c) Property damage to bus transit system bus(es), non-bus transit system vehicles, other bus system property or facilities, or any other property, except the bus transit system shall have the discretion to investigate events resulting in property damage less than $\$ 1,000$.

(d) Evacuation of a bus due to a life safety event where there is imminent danger to passengers on the bus, excluding evacuations due to operational issues.

(6)Each investigation shall be documented in a final report that includes a description of investigation activities, identified causal factors, and any identified corrective action plan.

(a) Each corrective action plan shall identify the action to be taken by the bus transit system and the schedule for its implementation.

(b) The bus transit system must monitor and track the implementation of each corrective action plan.

(7) Investigation reports, corrective action plans, and related supporting documentation shall be maintained by the bus transit system a minimum of four years from the date of completion of the investigation.

(8) On or before July 1, 2006, every bus transit system shall comply with the 2005 amendments to this rule.

\section{North Carolina}

The North Carolina Department of Transportation (NCDOT) requires that all their FTA grantees of Section 5307 (small urban), Section 5310, and Section 5311 programs notify the NCDOT Public Transportation Division of any major accident or incident by filling out the "Accident/Incident Notification Form” (Figure 1). Researchers interviewed four small transit systems in North Carolina. A number of these systems have a comprehensive incident investigation program in place that includes incident investigation policies and procedures, forms, grading policies, and guidelines and procedures for the incident review committees. A sample of this material is available on the accompanying DVD of the report and the Bus Safety Resource Guide website at www.cutr.usf.edu/bussafety. 


\section{ACCIDENT/INCIDENT NOTIFICATION FORM}

TO BE FILED IMMEDIATELY WITH PTD AFTER ACCIDENT OR INCIDENT

1. REPORTED BY:

(To be completed by transit system's director or operations manager)

2. TRANSIT SYSTEM NAME:

PHONE NUMBER: $(\quad)$

3. DESCRIPTION OF INCIDENT:

$\square$ Vehicle Accident

$\square$ Flood

$\square$ Bus/Transit line closure

Facility close down

Other:

4. DATE/TIME OF ACCIDENT/INCIDENT:

5. LOCATION OF ACCIDENT/ INCIDENT

(identify street, intersection, route no., river, railroad, city, county, state, etc.)

6. WERE THERE ANY FATALITIES?

$\square$ YES $\square$ NO IF YES, HOW MANY?

7. WERE THERE ANY INJURIES?

YES $\square$ NO

IF YES, HOW MANY? WERE ANY OF THESE INJURIES LIFE THREATENING? $\square$ YES $\square$ NO

IF YES, HOW MANY?

8. ANY PERSON(S) TRANSPORTED TO A MEDICAL FACILITY? WHAT MEDICAL FACILITIES?

$\square$ YES $\square$ NO

IF YES, HOW MANY?

9. WAS SERVICE STOPPED OR INTERRUPTED? WHEN WILL OR DID SERVICE RETURN TO NORMAL?

10. IF SYSTEM VEHICLES WERE INVOLVED, COMPLETE THE FOLLOWING*: DRIVER: VEHICLE MODEL YR

VEHICLE MAKE

VIN

MILEAGE



E

YR.

$\overline{(a t \text { time of accident) }}$
OPERATOR:

INSURANCE

IF THE VEHICLE IS TOTALED, FAX THE POLICE REPORT AND INSURANCE SETTLEMENT STATEMENT TO NANCY PAINTER @ 919-733-1391 AS SOON AS IT IS AVAILABLE.

11. WAS THE VEHICLE TRANSPORTED BY ANOTHER VEHICLE AWAY FROM SCENE AFTER THE ACCIDENT? $\square$ YES $\square$ NO IF YES, WHERE IS THE VEHICLE NOW?

12. IF YOU ANSWERED YES TO QUESTIONS 6,8 OR 11, THEN A POST-ACCIDENT DRUG AND ALCOHOL TEST SHOULD HAVE BEEN ADMINISTERED IMMEDIATELY*. WAS THIS COMPLETED? $\square$ YES $\square$ NO *WRITTEN RESULTS FROM TESTING SHOULD BE FAXED TO LES TWIBLE AS SOON AS THEY ARE AVAILABLE - 919-733-1391

$\begin{array}{ll}\text { 13. WHAT WERE WEATHER CONDITIONS? } & \square \text { CLEAR } \square \text { RAIN } \square \text { SNOW } \square \text { ICE } \square \text { SLEET } \square \text { FOG } \square \text { CLOUDY } \\ \square \text { OTHER }\end{array}$

14. WHAT WERE ROAD CONDITIONS? $\square$ DRY $\square$ WET $\square$ SNOW $\square$ ICE $\square$ MUDDY $\square$ OTHER

15. IF THERE WAS AN INCIDENT AT THE FACILITY, PRESENT DETAILS AND ANY DAMAGE:

DATE/TIME FACILITY EXPECTED TO RETURN TO NORMAL:

Figure 1. NCDOT Accident/Incident Notification Form 


\section{New York}

The State of New York’s Public Transit Safety Board (PTSB) is, by statute, responsible for investigating and analyzing serious transit accidents and recommending actions for reducing the occurrence of future incidents. The PTSB has broad, legislatively mandated powers to:

- establish accident reporting, investigation and analysis procedures

- conduct comprehensive accident investigations

- $\quad$ take a proactive role in public safety by reviewing, approving and monitoring system safety program plans submitted by each public transportation system

- $\quad$ conduct system safety program field audits

- analyze critical safety issues and concerns

- recommend the establishment of new safety legislation, rules and regulations, and transportation system procedures based on accident investigations, special studies and audits

In addition to meeting on a regular basis to review accident reports, investigations, and recommend new rules and regulations regarding such incidents, the Board's Safety Oversight Program makes on-site visits to the various statewide transit agencies to ensure adherence to system safety program plans and to conduct safety audits.

The PTSB has also developed an accident investigation training course, "Bus Accident Investigation Training for Identifying Safety Hazards" (B.A.I.T.F.I.S.H.). The New York B.A.I.T.F.I.S.H. program takes a three-step training approach that covers accident management and investigation, determination of preventability, and hazard assessment and mitigation.

Under current New York state law, each transit agency under the jurisdiction of the PTSB must be trained and certified in the B.A.I.T.F.I.S.H. courses to ensure it adheres to the latest safety and security requirements. Also, under state law, each transit agency under PTSB's jurisdiction must notify the PTSB of any of the following incidents:

- all accidents that result in a fatality

- all accidents that result in five or more injuries that require medical attention

The PTSB reviews transit accidents and produces an annual summary outlining identified types and causes of such accidents. From these analyses, the PTSB is able to make recommendations for bus driver training, bus vehicle designs, maintenance procedures to ensure supervisory and mechanic accountability, commitment of capital resources to improve safety deficiencies, emergency communications, preventive maintenance procedures, emergency plans and procedures, hours of service, and driver fatigue.

\section{South Carolina}

The South Carolina Department of Transportation (SCDOT) requires providers of public transportation, including rural operators, to report vehicle accidents when damage loss 
amounts to more than $\$ 1,000$. This is specified in the State Management Plan for stateadministered FTA program funds. Reports are submitted on South Carolina standard law enforcement accident report forms. The SCDOT does not become involved in any postaccident investigations or conduct any type of follow-up activities, including recommending corrective or remedial actions after an accident is reported.

\section{Texas}

The Texas Department of Transportation (TxDOT) requires that all FTA Section 5307 (small urban), Section 5310 and Section 5311 program grantees notify the Public Transportation Division (PTN) of each incident involving a transit vehicle used in the program. Section 5307 (MTA) transit providers are only required to report fatalities.

The PTN requires a Transit Vehicle Incident Reporting Form (Form PTN-101) (see Figure 2). The PTN-101 form notes that the incident description should include, but not be limited to, the following basic information: causal factors of the incident, the direction in which the vehicles were traveling, and road and weather conditions. Law enforcement reports are also being submitted when available.

Notification is made regardless of the funding source of the vehicle or whether the service is directly operated or purchased transportation. Notification can be done through mail, e-mail, or facsimile, within five days of the occurrence or discovery of each reportable incident. The information is reported directly to the district Public Transportation Coordinator (PTC), who then forwards the notification form and any additional documentation to PTN.

Each agency is required to report an incident when:

- $\quad$ an individual dies within 30 days of a transit incident

- an individual suffers bodily injury and immediately receives medical treatment away from the scene of the incident. Medical attention sought after leaving the scene of an incident is not reportable

- $\quad$ total damage exceeds $\$ 7,500$ (including other vehicles and property)

- transit vehicle incurs disabling damage as the result of the incident and is removed from revenue service

- non-arson fire occurs in any vehicle involved in the incident, revenue facility, or nonrevenue facility.

\section{Washington}

The Washington State Department of Transportation (WSDOT) requires all grant funded vehicles involved in an accident to submit the following information:

- $\quad$ nature of the incident

- level of damage to the vehicle

- copy of the accident report on file with local law officials

- copy of the investigation conducted by their organization 
- for vehicles purchased with FTA 5309, 5311, or 5311(f) fund, was post accident drug and alcohol tests conducted? If not, why?

- corrective measures are taken if the driver is found at fault

- depending on the nature of the incident, additional follow-up actions may be required, such as driver training for inclement weather, etc.

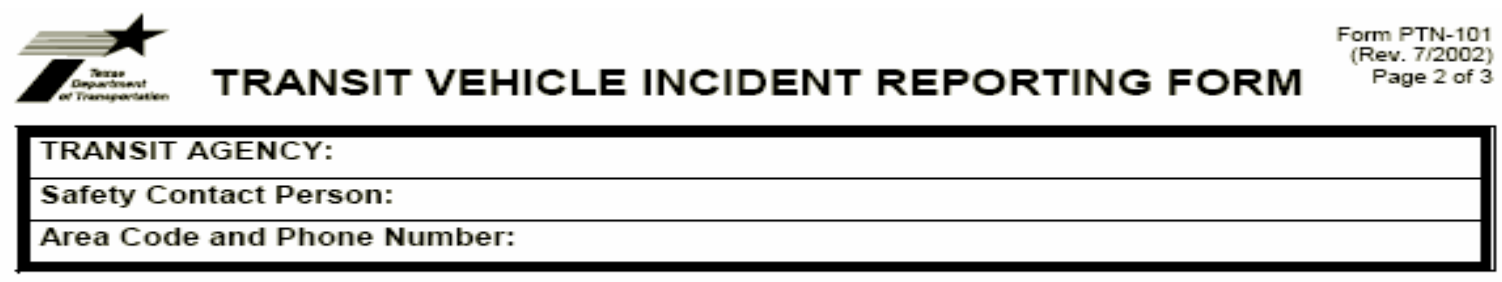

REPORTABLE FOR THE FOLLOWING REASON(S)

\begin{tabular}{|l|l|l|l||}
\hline Individual died & $\square$ & $\begin{array}{l}\text { Transit vehicle is towed away and removed } \\
\text { from revenue service }\end{array}$ & $\square$ \\
\hline $\begin{array}{l}\text { Injury requiring immediate medical } \\
\text { treatment away from the scene }\end{array}$ & $\square$ & Non-arson fire & $\square$ \\
\hline Total damage exceeded $\$ 7,500$ & $\square$ & & \\
\hline
\end{tabular}

\begin{tabular}{|c|c|c|c|c|}
\hline \multicolumn{2}{|l|}{ DATE of INCIDENT: } & INCIDENT TIME: & AM $\square$ & PM $\square$ \\
\hline \multicolumn{2}{|c|}{ ESTIMATED TOTAL DAMAGE: \$ } & COUNTY: & & \\
\hline \multicolumn{5}{|l|}{ LOCATION: } \\
\hline \# OF FATALITIES: & \# OF P & SPORTED FOR ME & REATN & \\
\hline
\end{tabular}

\section{AGENCY VEHICLE INFORMATION}

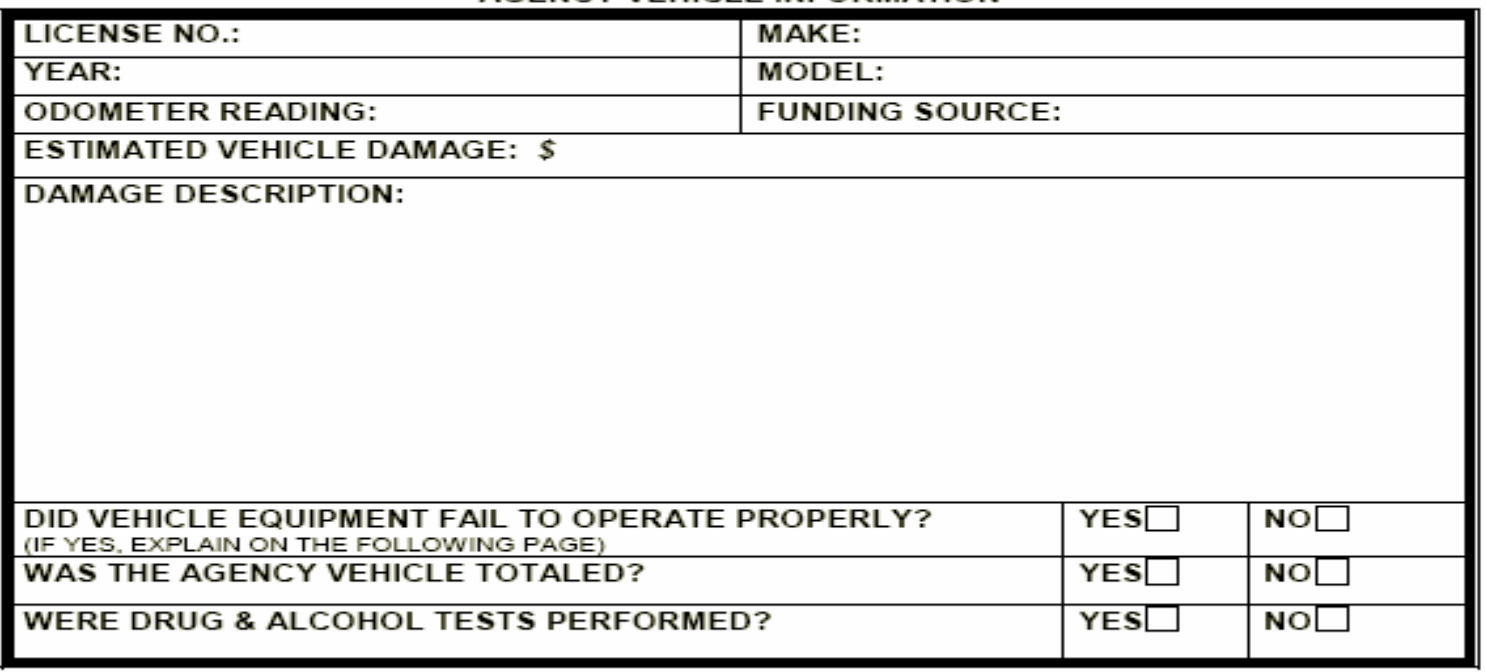

Figure 2. TxDOT Transit Vehicle Incident Reporting Form 


\section{Transit Event Investigation Training Video Overview}

The 42-minute Transit Bus Incident Investigation video provides transit systems with an overview of the procedures, guidelines and resources on how to conduct transit incident investigations. The video is available online at_www.cutr.usf.edu/bussafety/core/data or on the CD provided with this report.

The Transit Bus Incident Event Investigation Toolbox provides details on the roles and responsibilities of the operators, dispatchers, investigators, and supervisors. The operator's section of the toolbox explains the importance of understanding the agencies incident policies and procedures, the importance of reporting incidents, instructions on completing incidents/accident report forms, the seven basic emergency steps, and passing out courtesy cards.

The dispatcher's section of the Toolbox reinforces the importance of obtaining details about the incident including the location, number and type of vehicles involved, and the number of passengers on board and severity of injuries. This information is important in order to contact the necessary emergency response services and complete a dispatch incident report.

The Transit Bus Incident Event Investigation Video provides resources and materials for transit incident investigators and provides guidelines on how to conduct an incident investigation. Topics discussed in this video include evidence collection, tire marks, skids, fluids, contact and induced damage, exterior and interior damage, photographs, field sketching, vehicle fires, event data recorders, interviews, drug and alcohol testing, incident review boards, police reports, grading systems, and guidelines for recordability. These materials help focus the incident investigators attention to determine causal factors and establish corrective actions to prevent similar incidents in the future.

In addition to the video, the DVD and website provide samples of best practice policies, procedures, forms and template for incident investigation, along with a pocket guide for Transit Bus Incident Event Investigation a copy of the Transportation Safety Institute's (TSI) recently published "Guidelines to Determine Collision and Incident Recordability," and a copy of the "Florida Bus Incident Reporting, Tracking, and Analysis System” database. The Florida Department of Transportation, under contract with the Center for Urban Transportation Research, developed this tool to help rural transit agencies easily track, analyze and report accidents, security incidents, and other minor incidents.

The database allows a transit system to easily enter accident and security incident data into a standardized form, run queries, and view reports. The database provides transit systems the ability to analyze and report common trends in incident data over time. These documents are accessible on the accompanying DVD or the Transit Bus Safety Resource Guide Website at www.cutr.usf.edu/bussafety/core/data. 


\section{Transit Event Investigation Training Video Script}

Appendix A is the official Transit Event Investigation Training video script. The script served as the guide for the development of both the video and the resource website. 


\section{References}

“A Guide to Determine Motor Vehicle Accident Preventability,” National Safety Council 2004/2006.

"Bus Accident Investigation Training for Identifying Safety Hazards” ( B.AI.T.F.I.S.H.) New York State Public Transportation Safety Board

“Chapter 14-90, Equipment and Operational Safety Standards for Bus Transit Systems,” Florida Administrative Code (FAC)

United States Department of Transportation, Transportation Safety Institute "Fundamentals of Bus Collision Investigation” (FT00435)

United States Department of Transportation, Transportation Safety Institute "Intermediate Programs in Bus Collision Investigation” (FT00472)

United States Department of Transportation, Transportation Safety Institute "Bus Collision Prevention and Investigation Seminar” (FT00470).

Collier Area Transit, Collier County Florida

http://apps.colliergov.net/transadmin/atm/operations/cat/index.htm

Hillsborough Area Regional Transit Authority, Tampa, Florida

http://www.hartline.org/

Lakeland Area Mass Transit District (Citrus Connection) Lakeland, Florida

http://www.ridecitrus.com/content/

Lee County Transit Division (LeeTran), Fort Myers, Florida

http://www.rideleetran.com/default.htm

Pasco County Public Transportation, Pasco County, Florida

http://www.pascocountyfl.net/pubser/comser/PublicTrans/PTMAIN.htm

Pinellas Suncoast Transit Authority (PSTA), Pinellas County, Florida

http://www.psta.net/

North Carolina Department of Transportation, Public Transportation Division http://www.ncdot.org/transit/transitnet/

Buncombe County Mountain Mobility, North Carolina http://buncombecounty.org/governing/depts/Transportation/

Mitchell County Transportation Authority, North Carolina http://www.mitchellcounty.org/departments/transportation.html

Iredell County Area Transportation, North Carolina http://www.co.iredell.nc.us/Departments/Transportation/transportation.asp

Lakeland Area Mass Transit District (Citrus Connection) Lakeland, Florida http://www.ridecitrus.com/content/ 


\section{Acknowledgements}

Steven Dallman, U.S.D.O.T. Transportation Safety Institute

Joe Diaz and David Kelsey, Hillsborough Area Regional Transit Authority (HART), Tampa, Florida

Mike Gloss, Pinellas Suncoast Transit Authority (PSTA) Pinellas County, Florida

Dean Kirkland, Lakeland Area Mass Transit District Citrus Connection) Lakeland, Florida

Steve Neal, SunTran, Ocala, Florida

Peter Albrecht and Pattie Ralph, North Carolina Department of Transportation 
APPENDIX A 
BD549-22

August, 2007

\section{Bus Transit Incident Investigation Training Video Script}

\section{Introduction}

The Florida Department of Transportation and the National Center for Transit Research funded the development of this Incident Investigation Training Resource which was produced by the Center for Urban Transportation Research at the University of South Florida.

The purpose of this training resource is to provide transit systems with an overview of the procedures and guidelines needed to conduct transit incident investigations. This resource does not replace existing federally-offered training courses, but rather is intended to assist transit systems in implementing and complying with State requirements and best practices associated with bus transit safety and security incidents.

This training resource provides an overview of what to do when an incident occurs and an outline of the transit system's role in conducting an investigation. In addition, this resource will provide guidance to incident investigators to conduct and support an incident investigation. This material will focus on determining causal factors, arriving at a conclusion, and establishing corrective actions.

\section{Responsibility}

Transit system responsibilities for incident investigation start with an integrated incident prevention program. This program should include policies and procedures identified in the agency's system safety program plan.

The agency's policies and procedures provides guidelines for defensive driving, preventive maintenance, hiring and training, communication, handling of emergencies reporting, and other safety and security related functions. These policies are signed by the agency's management and are required to be followed by management, maintenance, operators and other employees in order to provide a safe environment for agency employees, volunteers, passengers and the general public.

All employees are expected and required to adhere to the policies and procedures adopted by their agencies to properly and diligently perform safety-related functions as a condition of employment. Procedures ensure that communications, responses, investigations, and corrective actions to transit incidents are thorough, complete and consistent. It is critical to not only have procedures in place, but also for transit system personnel to follow the policies and procedures adopted by the organization. These policies are to be reviewed and updated annually at a minimum or after an incident/ accident has occurred. 
Regardless of the type of incident, every transit agency should have a system in place for notifying, communicating and recording the information. The person involved in the investigation will vary depending on the agency, but will often include the general manager, safety and training manager, operation supervisor, dispatcher and the person responsible for drug and alcohol testing.

\section{The Operator}

Communication by the transit operator is critically important to initiating the investigation process. In any emergency, the operator's role is to manage the situation to the best of their ability by following the seven basic emergency steps:

- Stay calm

- Assess the situation

- Obtain help

- $\quad$ Protect people then property

- Reassure and assist the passengers

- $\quad$ Secure the scene

- Gather Information

Should an incident occur the operator should "Obtain Help” and start the process of incident investigation by notifying Management. Notification should be initiated by the operator involved in the incident with the notification made immediately to dispatch/supervisor or agency designated staff. The operator should shut down the bus, then provide the route number (if applicable), exact location, and vehicle number to Dispatch.

If shutting down the bus renders the radio inoperable, communicate with Dispatch first and then determine the need to shut down the bus. If Dispatch advises to shut down the bus and shutting down the bus will render the radio inoperable, be sure to set up with Dispatch how follow-up communications will take place, such as by cell phone. This is important, as lines of communication need to remain open for the update of information.

The operator should then activate the vehicle's four-way flashers and set reflective triangles in accordance with D.O.T. Safety Regulations.

If a security incident occurs, the operator is responsible for conveying any and all information about suspicious people, packages, devices or substances.

If the driver becomes incapacitated, emergency contact phone numbers may be posted on the bus. The operator:

- Should not discuss the incident with anyone except representatives from their agency and the police

- May provide their name, and the company name.

- Should show a valid Commercial drivers license only to law enforcement.

- Should not make any statements, regardless of the circumstance, or get drawn into any discussions or arguments. 
- Should not allow vehicles to be moved until someone arrives that can verify or witness the positions of the vehicles, length and position of skid marks, and lights on the vehicle.

Depending on the agency's policies and procedures, the operator may need to contact law enforcement and emergency medical transportation if necessary.

The operator should pass out Courtesy Cards to each passenger and/or witness.

The operator is responsible for completing an incident report. Incident reports should be completed as soon as possible after an incident. As time goes by, the operator's ability to recall specific details about the event will diminish.

Every incident must be reported to the agency, regardless of how minor it may seem. Failure to report an incident may be cause for disciplinary action, which will vary depending on the agency.

\section{Bus Fires}

Bus operators can and should perform several basic steps that can assist in the prevention of fires:

- Perform complete vehicle pre-trip inspection, including a check of electrical, fuel, and exhaust systems.

- Verify that fire extinguishers are on board, properly secured, and charged.

- During the day, check tires, wheels, and body for signs of excessive heat.

- Follow correct safety procedures for fueling, braking, and other activities that can lead to a fire.

- Monitor instruments and gauges often for signs of overheating.

- Use mirrors to look for signs of smoke from tires or the vehicle.

The four main signs an operator should look for should a fire occur:

- Burning odor

- Smoke

- Flames

- Visual or audible warning devices

It is important that the Seven basics steps to emergency management that were just discussed be employed by the operator should a bus fire occur.

Additionally, the operator should:

- Pull the vehicle off the road to a safe, open area, away from buildings, trees, brush, other vehicles, or anything that might catch fire.

- Leave enough room to evacuate the vehicle.

- Shift the vehicle into PARK or NEUTRAL as applicable. 
- Set the parking brake.

- Shut off the engine.

- Open all doors and leave the interior lights on if needed for evacuation.

- Evacuate all passengers.

- Position reflectors, unless it is unsafe to do so or your passengers require your assistance or attention.

- Put out the fire with your fire extinguisher, only if it is safe to do so.

Smoke inhalation causes more deaths than fire, so if the operator is unable to control the fire wait for emergency personnel. Equipment can be replaced. LIVES CANNOT!

\section{Vehicle Fire Investigation Procedures}

All fires should be investigated by a third party contractor, and it is important to obtain the fire department investigation report which needs to be incorporated into the agencies incident investigation. The results from the third party investigator should be shared with all affected personnel. It is important to subsequently develop an action plan that specifically addresses the fault and incorporate any changes to inspections, policies, or procedures immediately.

\section{Dispatch}

It is the main responsibility of the Dispatcher to complete a dispatcher's report once the operator reports an incident. The responsibilities of the dispatcher may vary from agency to agency. It is recommended that the following information be documented when an incident occurs.

- Driver's name

- Number of passengers onboard

- Time of incident

- Vehicle number

- Vehicle location

- Direction of travel

- Type of incident
- Number of vehicles involved

- Injuries (minor or major)

- Nature and severity of injuries

- Number of injuries

- Are emergency personnel required?

- Are police required?

- Are tow vehicles needed?

It may also be the responsibility of the dispatcher to contact law enforcement and emergency medical technicians (EMT) if necessary.

\section{Incident Investigator}

The investigator should be a person who has been trained in incident investigation techniques and is familiar with the agency's policies and procedures relating to defensive driving, preventive maintenance, hiring and training, communication, handling of emergencies, discipline, and other safety and security related functions. They should be able to evaluate evidence and reports, and identify the causal factors of the event. The incident investigator in many agencies may be the safety officer and/or the operations supervisor, the agency's director or a designated investigation team. However, this will vary depending on the size of agency and severity of the accident. 
Incident investigation training is available from USDOT's Transportation Safety Institute (TSI) which offers three federally certified training courses: "Bus Collision Prevention and Investigation Seminar," "Fundamentals of Bus Collision Investigation" and "Intermediate Problems of Bus Collision Investigation.”

\section{The Investigation}

An investigation should be done as close as possible to the occurrence of an event. It is essential that the response is immediate in order to secure, preserve, and capture the evidence before it deteriorates.

There are several tools that are needed to conduct an investigation. These tools should be kept a box in the trunk of the investigator car. These tools include:

- flash light and extra batteries

- camera with film and extra batteries

- rain gear

- latex gloves

- safety vest

- calculator

- clip board

- paper

- pencil

- spray paint

- tape measure

- measuring wheel

- $\quad$ tape recorder (in working order)
- hammer

- masking tape

- chalk

- courtesy cards

- radio

- cones

- Accident, Damage and Incident Report forms

- Drug and Alcohol Testing Notification form

- Sample Interview Questions

- Witness Statement forms

- Employee Incident Report form

Upon arrival to an incident scene, the investigator must secure the scene and collect facts about what has occurred. It is extremely important that the investigator assemble all the facts and information that are available.

The investigator should interview the involved operator as quickly as possible, after the collision. The operator's account of the collision should be written on the Operators Accident Report form and signed by operator.

When observing the incident site, the investigator is looking to determine possible cause(s) of accident and should note the path of the vehicles prior to the incident, what happened during impact, the final resting place of the vehicles, and what the operator did to prevent the incident.

It is also important to make note of:

- lighting and visibility

- obstructions or distractions 
- road surface conditions

- climate and weather conditions

- traffic signals and signs

\section{Collecting Evidence}

It is important for the agency's investigator to maintain control of the evidence. While on the scene of the incident, the investigator should collect and note evidence such as marks, debris, and fluid in and around the incident scene.

Roadway evidence is helpful in determining vehicle positioning and paths. This evidence consists of tire marks, roadway scars (scrapes, gouges), debris, markings that suggest the vehicle went airborne, and markings to other objects on or near the roadway.

All evidence must be marked with:

- date and time collected

- location

- identification of collector

Transferring of evidence should be done in writing and stored and accessed only by the investigator. Evidence should be stored in a secured location to prevent damaged or alteration

Deterioration of evidence can be caused by weather, the removal of vehicles to "open" the road, the separation of vehicles to aid the injured and the recollection of the human mind to recall what took place.

\section{Tire Marks}

Tire marks and roadway evidence are extremely important in determining how vehicles moved into the impact point and from the impact to their final resting locations. In collision investigation, tire marks are the equivalent of a fingerprint in a criminal investigation, and just as important.

\section{Skid Marks}

If the brakes are applied suddenly and with substantial pressure, the tires will lock. The heat dissolves or melts the tars and oils on the roadway surface, creating the distinctive dark smears commonly referred to as a tire marks, or skid marks.

On a concrete surface, road skid marks are lighter in color and are made by the rough concrete surface actually melting the tire.

The skid mark is created by a tire that is locked and is sliding not rolling. Skid marks tend to be straight, although can show curvature as a result of not all brake pads locking simultaneously or due to the crown of the road. This can cause the vehicle to depart from a straight-ahead path. (Front tire skid marks tend to be darker than rear tire marks.) 


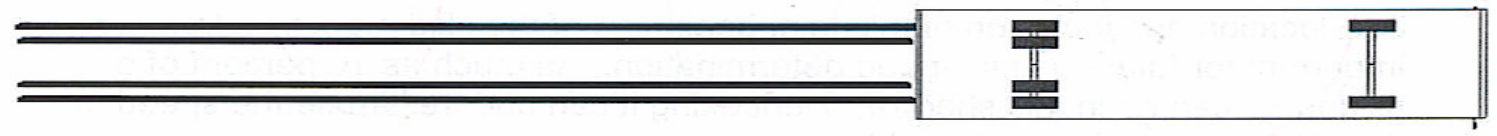

As evidence, skid marks show:

- Location and direction of travel for the vehicle

- The driver's intention to stop

- Possible evidence as to the speed of the vehicle

- Help to determine the area of impact by the offsets in the skid

Skid marks are an extremely important piece of physical evidence to the incident investigator. They can be used to determine speed and to establish the path of the vehicle while skidding. Tire marks as evidence are temporary and are affected by weather, sunlight, and traffic.

\section{Curved Skid}

A curved skid shows that the vehicle tires are rotating while at the same time skidding. When this happens, all four tire marks can be observed. This rotation during a skid can be initiated by the driver beginning a turning maneuver as wheels are locked in braking. The vehicle then continues in rotation. This could also be a result of unequal braking.

\section{Skip Skids}

Intermittent skid marks may have been made by a vehicle bouncing along on the roadway. The length of the skid mark and the length of the space between them is generally uniform and consistent, and less than 3 to 4 feet apart. This can occur when the wheel strikes a pothole or bump on the roadway, which starts the vehicle bouncing.

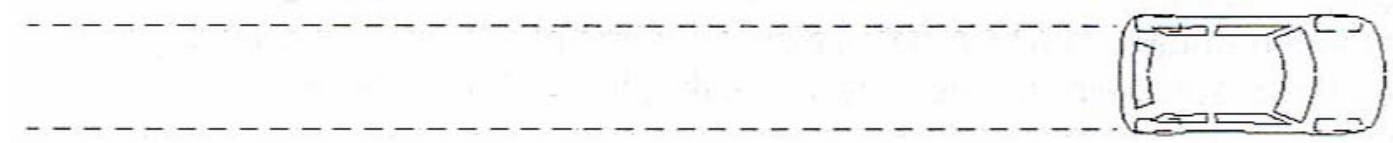

Skip skids should be measured for total length so that the gaps are included in the finished measurements. These gaps are considered to be a part of the overall skid mark. Vehicle braking is not reduced during the skip portion of the skid and the gaps occur by virtue of the wheels being off the ground for such short distances.

\section{Gap Skids}
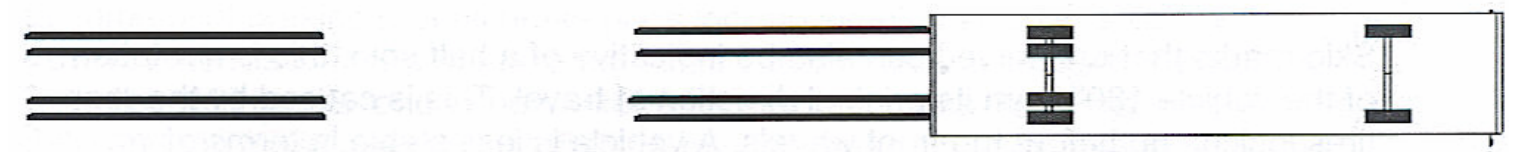
Gap skid marks are observed with a gap between the termination of the skid marks on the road way and a reappearance of the skid mark some distance down the roadway. This is the result of the driver applying the brakes, and releasing the brake and then re-applying the brake.

The driver may have momentarily released the brakes as they believed that the collision situation ahead, in which a collision appeared imminent, has passed. The driver then applies the brake again when they realize that the initial judgment was incorrect.

\section{Tire Tread Print}

The tire tread pattern indicates that the wheel was rolling and not skidding. The pattern of the tire rubber is imprinted on a flat surface without smearing. The print may be the result of loose matter picked up by the tire as it rolled on the roadway.

\section{Yaw Marks}

Yaw marks are tire marks left on the roadway by wheels that are sliding and rolling simultaneously.

Yaw marks are always curved and have very distinctive striations. As evidence, yaw marks show:

- A vehicle traveling too fast to negotiate a curve

- The vehicle's location and direction on the roadway

- Driver's intention to steer rather than to stop

- Determination of the speed of the vehicle

When a vehicle "spins out" while cornering, or is oriented in a direction different from its original direction of travel, Yaw marks will be deposited. Often they are in the form of light parallel grooves, referred to as striations or hash marks, which run straight but are diagonal to the outline of the continuous Yaw mark. They are made by the sidewall or rib of the tire. One of the most important pieces of information that can be obtained from yaw marks is the vehicle was taking a turn at a critical cornering speed and is on the verge of spinning out or slipping laterally.

\section{ABS - Brakes - Skid}

Anti-lock braking system (ABS) automatically prevents the wheels from "locking up" during braking, preserving vehicle stability and steerability. ABS brakes accomplish this goal by rapidly modulating the brake pressure. Vehicles equipped with ABS may leave faint, intermittent, visible skid marks. ABS-equipped buses do leave visible tire marks on the road, which are significantly lighter than those left by non-ABS vehicles. The tire faces are left with lightly colored abrasive marks. This evidence is very transient and will disappear within few rotations of the tire.

Debris as evidence is also important for an incident investigation. Investigators should observe the under body of the vehicle for drag marks, ice and/or water accumulation, and other objects such as vehicle parts. Significant attention should be paid to head lights and bumpers. 


\section{Vehicle Fluids}

Vehicle fluids will also provide valuable evidence. Fluid type and dispersal of these fluids are important. Investigators should note if fluids dribble, puddle, run off or splash down.

Vehicle fluids evidence types include:

- Splash down - occurs when a fluid container is ruptured and fluid splashes onto the surface.

- Dribble - fluid left in a "trail" from the area of impact to the vehicle's final rest.

- Puddling - fluid forms in a puddle after leaking from the vehicle, generally under and around the vehicle.

- Run-off - fluid leaks from the vehicle and runs down a grade.

- Soak in - fluid leaks from the vehicle and soaks into porous surface such as soil or gravel

\section{Contact and Induced Damage}

Contact damage is damage to any part of the vehicle caused by direct contact with some other object. This object can be another vehicle, a pedestrian, a fixed object, or even the road surface itself.

External contact damage is shown by rubbed-off and/or crumpled vehicle skin, tire rubber, road material, tree bark, and even human tissue or clothing. It is also indicated by imprints of headlight housings, wheel rims, bumpers, door handles, poles, and other fixed objects.

Induced damage is damage that is caused by the vehicle being hit in one area and the vehicle reacting in another. An example would be the roof of a vehicle buckling when the vehicle is hit on the front end or parallel fractures or a checkerboard patterns on a front windshield.

Contact damage to vehicle glass has specific effects depending on the type of glass involved. Contact damage on safety or laminated glass used in the front windshield will leave fracture lines radiating away from the contact point. These circular lines formed what has been described as a "spider web" pattern. In addition windows on the side and in the rear of the vehicle are typically not tempered and will simply shatter leaving no pattern marks.

\section{Exterior Damage Assessment}

After assessing the final positions of the vehicles, the investigator should determine if the damage present is consistent with their understanding of the collision in terms of vehicle orientation and dynamics. Many collisions which are listed as single impacts will actually involve more than one impact, for example the vehicle bounces after impact into a fixed object, or vehicles may rotate quickly after impact and contact each other for a second time. Collision damage to the vehicle is helpful in determining how the object was struck. In vehicle-to-vehicle impacts, the investigator should look for damage that matches both vehicles. 
Damage to wheels and tires of vehicles also require careful examination. Many times a driver will claim tire failure as being the cause of the loss of control leading to the collision. The investigator should attempt to determine tire damage caused by the collision, as opposed to damage existing prior to the collision or while the vehicle was being removed from the collision scene. Roadway tire marks often indicate tire failure prior to the collision. This can be seen in the form of a flat tire or wobble scuff marks. These scuff marks indicate that the deflated tire was being distorted between the road and the rim as it rolled flat along the roadway.

Blowouts that precipitate a collision exhibit unique and distinctive characteristics. Tire blowouts show characteristics that appear to have been caused by the explosive deflation of the tire, which result in ruptured cord fiber ends being frayed and fuzzy, as if torn apart by a great force. A blowout may occur before impact, during impact, or after impact. Fresh cuts or slits in the tire are associated with collision damage resulting from sharp metal edges coming in contact with the tire.

\section{Photographing the Scene}

Whether you use a digital camera, 35 millimeter single lens reflex (SLR), single use "throw away" camera, or an "instant" camera, photography is an important part of the collision investigation. When done properly, photography can:

- Record visual proof of violations of procedures or laws

- Record information for later use

- Assist memory

- Be used to support or discredit witness statements

- Show relationships between one or multiple objects

- Identify vehicles and locations

Photographs should be taken as soon as possible after arriving on the scene of the incident. Photos should be taken of those things that will change quickly. While photos are very useful, they are not a substitute for written information, or a field sketch.

Investigators should take distance picture first, then move in and take the close-up pictures, avoiding angles that distort what the scene really looked like. If your agency's vehicle was parked or stopped at the time of the collision, take a picture or pictures showing that the vehicle was legally parked or stopped.

In general, take pictures of the following:

- Overall scene

- Area of impact

- Fixed object damage

- Sight lines or distances

- Sight obstructions

- Sun position

- Evidence

- Point of final rest 
- Tire skid marks

- Debris

- Fluids

- Other conditions or items that may be of importance

- Location signs/road signs, traffic signals/stop signs, vehicles model/ license plates

- Photos showing close-up or detailed areas of damage, matching damaged parts of two vehicles showing how they came in contact, or any other items on the vehicle that can help explain the collision

- Maintain negatives and/or CD of photos with the investigation report

\section{Field Sketching}

Investigators should draw a field sketch of the collision scene showing certain features of the crash, such as the intersections, vehicles, street names, directions, traffic signals and signs position of witnesses and any other objects that might be useful.

It is important for the investigator to use a plain piece of paper when illustrating the field sketch. Investigators should include on their field sketch directional north, any and all measurement and a statement that reads "not to scale."

\section{Event Data Recorders}

Another tool that can be used in incident investigations is the Event Data Recorder or the "black box." In Florida, all new small buses procured under the Florida Vehicle Procurement Program are equipped with this unit. The Event Data Recorder can be programmed to automatically store the higher level of data required for incident investigation. Once the unit recognizes that an incident has occurred, it stores all data from 45 seconds prior to the incident until the vehicle comes to rest.

By querying the data held within the event recorder, data can be extracted to tell what a driver /vehicle was doing for up to 45 seconds prior to the incident in great detail. This information includes vehicle speed, engine speed, lateral and longitudinal accelerations, (braking /accelerating /swerving) as well as operation of vehicle equipment / signals etc. The data is saved in its raw form and is viewable using Microsoft Access database software.

\section{The Interview Process}

Interviewing, both at the scene of the collision and afterward, is an important component of collision investigations.

Interviews may be conducted with operators, drivers of other involved vehicles, non-involved witnesses, police, fire, EMS, passengers and maintenance personnel. Although it is best to conduct interviews at the scene, there are times that they may need to be conducted later. Later interviews may be conducted over the phone or in person, but it is preferred that they be done in person at a neutral location. 
If possible, record the interview (whether on the phone or in person). Make sure you ask permission to record the interview prior to beginning the process. Once the interview begins, be courteous and patient. If the interviewee is a witness to the collision and not directly involved, they are under no obligation to speak with you and should be treated with respect.

It is important when interviewing to listen more than you speak, to ask open ended questions, and to take notes. You should not write the statement for the witness, but assist them in filling out the statement form. You may ask them to identify sequences of events and have the witness draw sketches of the scene.

\section{Drug and Alcohol Testing}

Federally-funded public transit systems must comply with regulatory requirements, establish and maintain a drug-free workplace, and test safety sensitive employees for prohibited drug use and alcohol misuse throughout their tenure of employment.

Regulations have been written to establish strict guidelines and rules involving all aspects of drug and alcohol testing programs. The regulations include specifics on when an employer must conduct drug and alcohol testing following an accident or incident.

Testing employees for prohibited drug use and possible alcohol misuse is required after all accidents or "incidents" that meet the FTA established criteria. The transit system's Drug and Alcohol Program Manager or Designated Employer Representative must be trained to identify which accidents meet the FTA thresholds for drug and alcohol testing; this individual should be notified immediately, following any accident or incident.

All safety-sensitive employees whose actions could have contributed to the accident are subject to post accident drug and alcohol testing when the FTA criteria to test are met. This may include operators, mechanics, dispatchers and others.

If it is determined that post-accident drug and alcohol tests are required, the testing must be performed as soon as possible following the accident.

If an alcohol test is not administered within 2 hours following the accident, the employer must still attempt to administer the test. In addition, the employer must prepare and maintain on file a record stating the reason(s) the test was not promptly administered.

If an alcohol test is still not administered within 8 hours following the accident, the employer shall cease attempts to administer an alcohol test and shall maintain records as to why the test was not performed. Likewise, if a drug test has not been performed within the first eight hours following the accident, the employer must document the reason for delay and continue to attempt to administer the test. After 32 hours, the employer must cease attempts to conduct the drug test and document why the test was not performed. 
The circumstances that require a post-accident test for drugs are the same circumstances that require a post-accident test for alcohol.

Every accident that meets the FTA accident definition must result in both a drug and alcohol test.

\section{Guidelines for Recordability}

The Transportation Safety Institute (TSI) recently published the "Guidelines to Determine Collision and Incident Recordability." TSI's intent in developing these guidelines has been to develop a tool to assist transit agencies in determining recordability/preventability of collisions and incidents, based on a high standard of defensive driving. The guide provides a series of situations and incident scenarios along with examples of action that would make it a recordable. While this resource serves as a valuable guide, and details a variety of situations and incidences, it is not possible for every collision and incident that may occur to be addressed. Therefore there is a great deal of leeway or discretion provided to a transit property, including the discretion of a company adopted definition of the word "reasonable."

A recordable collision is one that occurs because the operator fails to act in a reasonably expected manner to prevent it.

Failure to learn what caused a collision or incident increases the chance of similar incidents occurring in the future. An investigator should examine each incident as recordable and determine whether the operator drove defensively and demonstrated an acceptable level of skill and knowledge. The judgment of what is reasonable should be based on an agency adopted definition, thus establishing a goal for its safety management.

\section{Incident Review Board}

It is recommended that all transit systems regardless of size or location have an Incident Review Board or committee. A Review Board is established to allow a committee decision on the recordability of a collision rather than allow one supervisor to make the decision. The Review Boards take any personality conflicts and preconceived bias out of the decision making process, determine recordability of the incidents, and recommend steps to be taken to prevent similar events in the future.

Members of the Incident Review Board should have an understanding of and experience with the agency’s policies and procedures, defensive driving, maintenance, and training programs.

Incident Review Boards are generally composed of three to seven members (usually an odd number) that meet at intervals which allow them to consider incidents on a "current event" basis. Board membership should include operator representatives, management representatives, and a supervisor assigned safety responsibilities. An outside person such as a representative from the insurance company or risk manager may be asked to be a member of the board. Rotating of all board members is recommended to promote a wide interest in the safety program, and members should not serve more than two years. Incident Review Board set-up will vary depending on the 
agency. The primary role of the safety manager is to chair the review board. The chair presents the facts of the incident and outlines the reasons for considering the incident recordable.

Meetings are held at times that are convenient for all board members. Each member is provided with a copy of all written reports such as: the driver's report, police reports of the incident and any other information that might be helpful in making a decision of the recordability of the incident. The involved operator may appear before the board to state their own case and present any views points on the facts. The operator should be asked to leave before the vote on recordability is taken.

A written record should be made of the board's decision and the reasons for decision, as well as a record of any recommended corrective actions. All corrective actions recommended by the board should be discussed in open safety meetings with all operators. The same material can be used for in-house publications, bulletins, and operator training. Existing training programs and refresher training may need to be changed or added based on the cause or contributing causes of the incident.

When maintenance deficiencies or vehicle/equipment failure are found to be the cause of the incident, a corrective action plan should be developed to prevent similar events in the future. The corrective action plan may include changes to policies and procedures related to maintenance, as well as changes to existing and refresher maintenance training.

\section{Police Report}

Police reports will be important reference documents during the investigation process. These reports should be used, filed, referenced and utilized as tools for the investigators final findings. Police reports can be used to identify causal factors and to develop recordable accident and disciplinary policies. Police reports should not be a transit system's sole source for incident investigation, but rather serve as a supplemental resource.

\section{Grading System}

Each agency should have in place a grading policy that addresses negligent acts which results in recordable/ preventable injuries or incidents to employees, passengers or the general public.

Disciplinary policies are set by the transit agency or local government agency. The types of disciplinary actions for preventable incidents vary greatly from agency to agency, depending on the agency and the severity of the incident. It is important for each agency to have a grading policy in place, to enforce the policy, and to stick to the policy for all employees.

Following is an example of what a disciplinary action policy might look like:

\section{First Occurrence}

A verbal warning or a one-day suspension including retraining and a written warning

\section{$\underline{\text { Second Occurrence }}$}


One-day suspension and a written warning, or up to 5 days suspension and a written warning thatone more preventable will be grounds for termination within 12 months of the first preventable.

\section{Third Occurrence}

Terminated or a written warning and three day suspension.

\section{Fourth Occurrence}

Termination

\section{Forms}

As part of the Incident Investigation Toolbox Resource, best practices, sample forms and templates are provided on this DVD for your reference.

The Florida Department of Transportation under contract with the Center for Urban Transportation Research developed a tool to help transit systems easily track, analyze and report accidents, security incidents and other minor incidents.

The tool utilizes Microsoft Access and allows transit systems to easily enter accident and security incident information into a standardized form, run queries, and view reports. Agencies can use the existing fields, queries and reports in the database reports or customize them to meet their agency's needs. The database provides transit systems with the ability to analyze and report common trends in incident data over time. Transit systems can then identify changes to existing driver training programs and/or the need for refresher training based on the types and frequency of incidents. The database is available on-line at www.cutr.usf.edu/bussafety/core/data.htm ,Bus Incident Reporting Database.

\section{Conclusion}

Incident investigation is an important part of transit system management. This resource has provided a brief overview of methodologies, policies, rules and procedures for incident investigation. However, it is recommended that transit incident investigators further their knowledge base by attending federally- supported investigation classes from organizations such as the USDOT's Transportation Safety Institute.

We encourage you to review the file content of this DVD for forms, templates, policies, procedures, and other documents that can serve as resources during the incident investigations. These documents along with video are available on the Transit Bus Safety Resource Guide Website under "Safety Data Acquisition and Analysis." 